\title{
Approach to Patients with Neurotrauma and Thoracic Trauma and Anesthesia Management with Current Guidelines -1
}

\author{
(D) Tarkan Mıngır1, (D) Cansu Kılınç1, (D) Seray Türkmen¹, (D) Mustafa Erdal2, (D) Anlayış Aksu³, (D) İdris Avcı², (D) Selim Şeker², \\ (D) Namigar Turgut ${ }^{1}$ \\ 1 Universty of Health Sciences, Istanbul Okmeydani Training and Research Hospital, Department of Anesthesiology and Reanimation, Istanbul, Turkey \\ 2 Universty of Health Sciences, Istanbul Okmeydani Training and Research Hospital, Department of Neurosurgery, istanbul, Turkey \\ 3Universty of Health Sciences, İstanbul Okmeydani Training and Research Hospital, Department of Thoracic Surgery, Istanbul, Turkey
}

\section{Abstract}

There are many causes of trauma such as traffic accidents, work accidents and falling from height. These patients require systematic management in post-traumatic evaluation, airway management, resuscitation, possible surgical procedures, intensive care follow-up and treatment. The nature of the trauma, post-traumatic uncontrolled bleeding, coagulation anomalies, hypothermia, shock and acidosis disrupts the normal homeostatic mechanism and is associated with poor clinical outcome. Other paradox in trauma patients is the necessity for emergency intervention with insufficient medical history information of the patient and unclear trauma type. In this review, it was aimed to discuss the general management and anesthesia management of patients with neurotrauma and thoracic trauma in the light of current guidelines.

Keywords: Neurotrauma, thoracic trauma, anesthesia, guidelines

\section{INTRODUCTION}

In our country, approximately 7000-10000 people die after head and/or spinal trauma. The leading causes of death and permanent disability in this patient population are head trauma, hemorrhages, sepsis and multiple organ failure. Mortality rates due to severe head trauma have decreased significantly in recent years, being $20-30 \%$. In addition to advances in computerized tomography $(\mathrm{CT})$, early surgical intervention, intracranial pressure (ICP) and perfusion pressure monitoring, and progresses in intensive care unit, the increased understanding of the harmful effects of hypoxia, hypotension and hypoperfusion on the brain has undoubtedly played an important role. The algorithms applied in the early diagnosis and intervention process for the centers serving more patients play an important role in reducing the morbidity and mortality rates.

\section{NEUROTRAUMA}

\section{A. Head Trauma}

Patients with major trauma are primarily evaluated with ABC criteria, Airway, Breathing and Circulation, followed by evaluation of Glasgow Coma Scale (GCS) (Table 1). Patients with GCS $\leq 8$ account for only $1 \%$ of all cases (1). Rapid imaging for advanced examination is the second stage. Patients with minor head trauma, good general condition and GCS: 15 usually do not require additional advanced imaging, while patients with $\mathrm{GCS} \leq 14$, confusion and neurological deficit undergo advanced imaging modalities. CT is the first choice in intracranial hemorrhage and cranial fractures. The most common pathology of the skull is fractures. Most of them are linear nondisplaced fractures and discharged after 24-hour clinical follow-up. Emergent surgery is considered for patients with displaced fractures $\geq 10 \mathrm{~mm}$, open wound and cerebrospinal fluid (CSF) leakage (2). 
Traumatic subarachnoid hemorrhage (SAH) is the most common hemorrhage in intracranial hemorrhages with a rate of $2.5 \%$ (Figures 1a, 1b, 1c, 1d, 1e.) (3). This is followed by hemorrhagic contusion, subdural hemorrhage (2\%) and epidural hematoma (1\%). Clinical manifestations of traumatic SAH range from asymptomatic patients to comatose patients. Support should be provided with clinical follow-up. Most contusions represent an abrupt acceleration and deceleration of the head, causing the brain to collide with the inner surface of the skull (coup-contre coup lesions). While most of the patients are discharged after anti-edema treatment and follow-up, some patients underwent surgical decompression due to the pressure effect and developing raised ICP.

Subdural hemorrhages occur in acute and chronic forms. Acute subdural hemorrhage occurs after tearing of the bridge veins and parenchymal damage in high-energy head traumas. There is a $60 \%$ mortality risk. While small subdural hemorrhages are managed conservatively, subdural hemorrhages that are $\geq 1 \mathrm{~cm}$ or that create ventricular shift undergo emergency surgery. Chronic subdural hematoma usually presents with a more insidious symptomatology. Elderly patients, infants or patients with coagulopathies usually present with unilateral motor deficits and headache following head trauma. They may be unilateral or bilateral and require urgent neurosurgical intervention. Surgical technique is based on the drainage of the hematoma by unilateral/bilateral burr holes or craniectomy. Epidural hemorrhage develops after rupture of the epidural arteries (especially middle meningeal artery) following skull fracture after head trauma. Although the patient's general status at the time of admission is fine, the patient may suddenly worsen and become comatose. This phenomenon is known as the lucid interval. Epidural hemorrhages $\leq 10 \mathrm{~mm}$ can be followed, while larger diameter hematomas are decompressed surgically. The intracranial localization of the hematoma (such as temporal or posterior fossa localization), as well as the hematoma volume, is indicative in the surgery of epidural hematomas.

The supportive treatment of hospitalized patients with severe head trauma, confusion and intracranial hemorrhage starts with head position. In order not to disturb the cerebral blood circulation, the head is held at 30 degrees in neutral position, the patient's oral intake is discontinued and isotonic fluid support is given. The hemoglobin value should not be below $10 \mathrm{~g} / \mathrm{dL}$ in order not to impair cerebral perfusion. Blood pressure should be kept between 120/80-160/90 mmHg. The risk of intracerebral hemorrhage increases with hypertension and the risk of cerebral hypoperfusion increases with hypotension. If cerebral edema is detected in the patient, mannitol or hypertonic saline is administered at a dose of $0.25-1 \mathrm{~g} / \mathrm{kg}$ within 20 minutes. Because of cytotoxic edema, there is no use of glucocorticoids such as dexamethasone after head trauma. Since intubated patients with a GCS of $\leq 8$ cannot be followed up, ICP monitoring should be performed. "Cerebral perfusion pressure: mean arterial pressure -ICP" formula is the main and indispensable formula of patient follow-up. While ICP changes with age in normal individuals, the
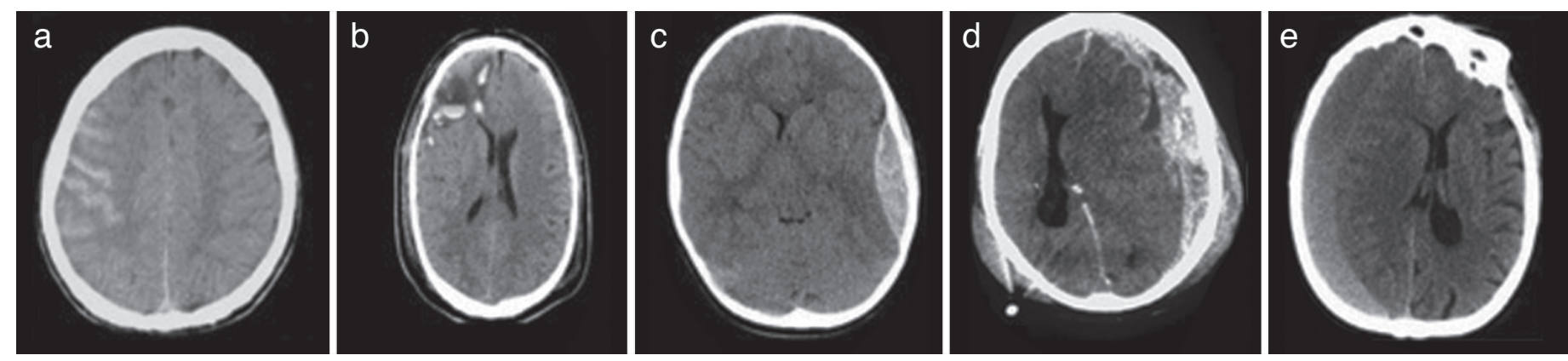

Figure 1. a) Traumatic subarachnoid hemorrhage, b) contusion, c) epidural hematoma, d) subdural hematoma (acute) and e) subdural hematoma (chronic)

\begin{tabular}{|l|l|l|}
\hline Table 1. Glasgow Coma Scale & Motor response \\
\hline Eye response & Verbal response & Obeys commands $(+6)$ \\
\hline Spontaneously $(+4)$ & Oriented $(+5)$ & Localizes pain $(+5)$ \\
\hline To verbal command $(+3)$ & Confused $(+4)$ & Withdrawal from pain $(+4)$ \\
\hline To pain $(+2)$ & Inappropriate words $(+3)$ & Decorticate response $(+3)$ \\
\hline No eye opening $(+1)$ & Incomprehensible sounds $(+2)$ & Decerebrate posture $(+2)$ \\
\hline & No verbal response $(+1)$ & No motor response $(+1)$ \\
\hline & & \\
\hline
\end{tabular}


normal value in adults is $8-12 \mathrm{mmHg}, 3-7 \mathrm{mmHg}$ in pediatric population and 1.5-6 mmHg in newborns (4). If ICP cannot be lowered despite all anti-edema treatments, ventricular drainage, barbiturate coma, and, finally, decompressive craniectomy can be used in patients with an ICP $>20 \mathrm{~cm} \mathrm{H}_{2} \mathrm{O}(5,6)$. Morbidity and mortality rates are extremely high in these patients. Patients with post-traumatic hydrocephalus are followed with external ventricular drainage (4).

The use of prophylactic antiepileptic drugs is always controversial despite intracranial hemorrhage due to head trauma. While some centers begin prophylactic antiepileptics, antiepileptic medication is recommended in recent publications if the patient experiences two seizures more than 24 hours apart (7). Diphenylhydantoin was the first option in the past with a bolus dose of $15-20 \mathrm{mg} / \mathrm{kg}$ in $150 \mathrm{cc}$ saline (not to exceed $50 \mathrm{mg} / \mathrm{kg}$ per minute) and a maintenance dose of $3 \times 100 \mathrm{mg}$, levetiracetam 2x500 mg is widely used nowadays due to being non-hepatotoxic and having less side effects.

\section{B. Spinal Trauma}

According to ultrasonography data, the incidence of posttraumatic spinal cord injury was reported to be 40/1000000 and 12,000 annually (8). Traffic accidents are the leading cause. This is followed by falls from the height and assaults (9). Patients are admitted to our emergency department on a trauma board by an ambulance and cervical collar is applied by emergency personnel. After the $A B C$ evaluation and general examination of the patient, neurological examination is performed. The impairment scale developed by American Spinal Injury Association (ASIA) is used by our neurosurgeons to assess the degree of trauma (Table 2). Patients often describe pain in the midline at thoracic and lumbar spinal levels. Spinal neurological damage should be suspected in the presence of sensory or motor deficits in the extremities or urinary and stool incontinence.

In our practice, the first imaging modality to be asked is CT because of its sensitivity in bone tissue. Depending on the location of the examination, local CT or whole spinal CT may be requested. Spinal column is evaluated in 3 separate sections as anterior, middle and posterior columns. Fractures on the anterior colon, and transverse process and spinous process fractures are usually followed only by analgesic treatment and braces, while the fractures in the vertebral bodies are indications for hospitalization. The compression rate and spinal cord compression should be examined carefully. The cases with less than 50\% compression are managed conservatively with thoracolumbar brace at outpatient follow-up, while surgery is planned in patients with $>50 \%$ loss of height (Figures $2 a$ and $2 b$ ) or $30 \%$ or more spinal canal involvement and free bony fragment in the canal (Figures $3 a$ and 3b). According to the general condition of the patient, surgery is planned for decompression and stabilization within the first 24-48 hours. The presence of

Table 2. ASIA spinal trauma assessment scheme

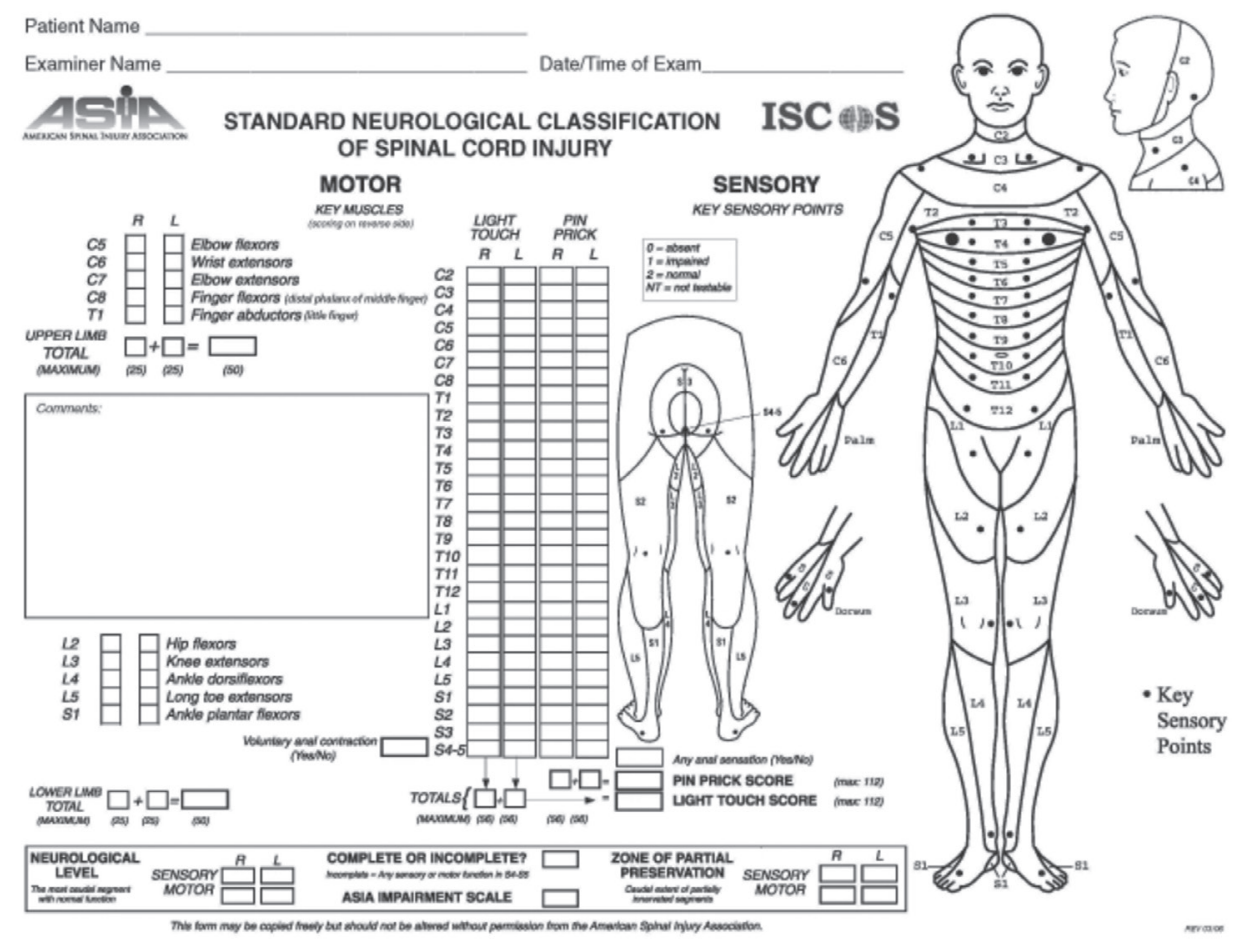


simultaneous thoracic trauma is the main reason for postponing the surgical intervention. If a motor-sensory deficit due to spinal trauma is considered, high-dose methylprednisolone protocol is started. If the trauma occurs within 8 hours, $30 \mathrm{mg} /$ $\mathrm{kg}$ methylprednisolone is delivered with bolus infusion for 15 minutes. Then, $5 \mathrm{mg} / \mathrm{kg}$ is started as maintenance dose in 24 hours. The patient should have gastrointestinal hemorrhage prophylaxis and blood glucose monitoring. The maintenance dose is extended up to 48 hours if the hospital admission is after 8 hours. Although the exact benefits of the methylprednisolone protocol have still not been confirmed, there are publications in the literature showing that there is significant recovery in motor and sensory deficits in the first 8 hours, despite the possibility of an additional high complication rate (10).

In conclusion, a significant part of the experimental and clinical trials in the last 20 years have focused on cell biochemistry and genetics to further understand the pathophysiology of head trauma, and it is thought that the developments in this area will contribute greatly to directing clinical treatment in the future. As being the members İstanbul Okmeydanı Training and Research Hospital, one of istanbul's and Turkey's most patient serving center, approaching the head and spinal traumas based
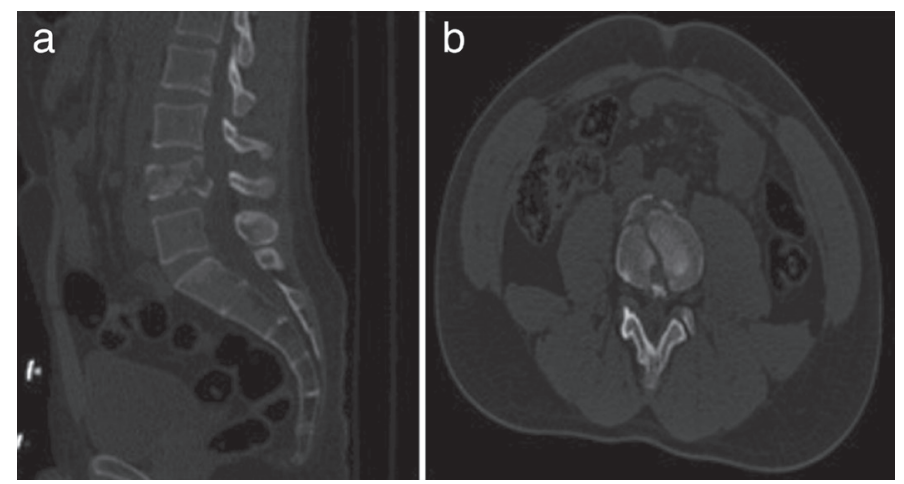

Figure 2. a,b) L4 vertebrae compression fracture in sagittal and axial computerized tomography sections. Free fragment is observed in the spinal canal
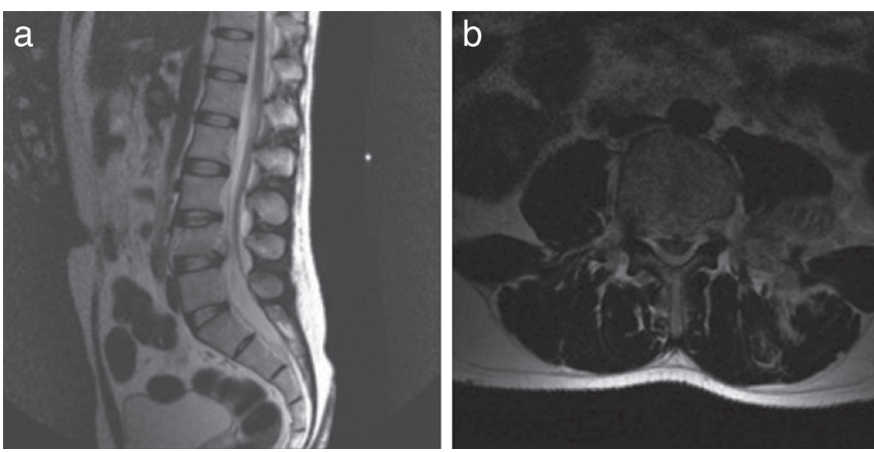

Figure 3. a,b) Sagittal and axial magnetic resonance imaging sections of the same patient on current guidelines will provide a faster and more systematic evaluation of the patient, and will help us reach the desired numbers in morbidity and mortality rates.

\section{THORACIC TRAUMA}

Thoracic traumas are an important cause of mortality and morbidity in adults and children. It is the leading cause of death in patients with multiple traumas with a rate of $25 \%$, but this rate decreases to $1 \%$ in isolated thoracic penetrating injuries not accompanied by cardiac injury. The first aim of the approach to thoracic trauma is to eliminate the situations that may result in death in a short time. According to etiology, thoracic trauma is divided into blunt and penetrating trauma. Specific injuries include pulmonary barotrauma, burns of the tracheobronchial tree resulted from aspiration, blast lung injury, parenchymal lung damage from aspiration and iatrogenic injuries. Rib fractures with blunt trauma may involve lung contusions, lacerations, or rupture. In addition to such direct damages, it may also be secondary to disintegration of the tissue (air embolism resulting from the entrance of air into the pulmonary veins after lung laceration) (11).

The most common cause of blunt trauma is traffic accidents (70\%). Penetrating thoracic traumas occur as a consequence of side arms or firearms and are classified into three groups $(12,13)$ :

1. "Sleeper" wounds (no exit wound)

2. Perforating wounds (entrance wound and exit wound)

3. Wounds in which the projectile penetrates through the whole intra-thoracic cavity and remains in the subcutaneous tissue.

It should be always borne in mind that all penetrating traumas are in direct communication between the external environment and the pleural space. If the defect is large, an open pneumothorax occurs. In small defects, wounds close spontaneously due to the contraction of muscle or blood clotting. However, this may cause tension pneumothorax and empyema, making the patient more complicated (14-16).

\section{Pathophysiology of Thoracic Trauma}

Traumatic force with thoracic trauma impairs lung function by causing:

-Disorder in the mechanics of breathing: caused by rib fractures and flail chest. Accompanied with hypoventilation, atelectasis, difficult expectoration of sputum from the tracheobronchial tree, the development of bronchopneumonic complications, acute respiratory failure and even death, especially with elderly 
patients. Collapse of the lungs due to hemo- or pneumothorax leads to arteriovenous shunt and hypoxia (11-14).

-Disruption in ventilation-perfusion relationship: oxygenation cannot be performed with the lung collapse or mechanical obstruction of the large airway. Systemic hypoxia occurs. This lung damage may cause vascular thrombosis or massive fat microembolism, disseminated intravascular coagulation (DIC) and acute respiratory distress syndrome (ARDS) (10-16).

-Gas exchange abnormalities of alveolocapillary membrane: the alveolocapillary membrane is composed of the surfactant layer, the surface of macrophages, alveolar epithelium, the interstitial space and the capillary endothelium. In thoracic trauma, direct damage to the alveolocapillary membrane may occur, as in the case of lung contusion, smoke inhalation, aspiration of gastric contents, heart failure and pulmonary interstitial edema (12-16).

\section{Surgical Approach to Thoracic Trauma}

The main task of the surgeon is to determine the mortality risk of the wound and determine the type of the intervention. Conditions requiring hospitalization include (11-17):

-Airway obstruction

-Massive hemothorax

-Tension pneumothorax

-Open pneumothorax

-Flail chest

-Cardiac tamponade

-Massive bilateral lung contusion

-Elderly patient with multiple fractures

Thoracotomy or thoracoscopy are indicated in the cases of (1820):

-Open pneumothorax

-Penetrating injuries due to foreign bodies

-Bleeding complications of chest drain

-Massive hemoptysis

-Continuous air leak from the chest drain and permanent collapse of the lung

-Tracheobronchial injury

-Cardiac tamponade

-Damage to large blood vessels and heart
-Diaphragm and esophagus injuries

-Empyema due to complication of the injury

The surgeon must first decide rapidly by physical examination. Radiological imaging and laboratory tests are time-consuming in severe cases. Clinical judgment is needed to decide upon the necessity for tracheostomy, chest drainage, emergency pericardiocentesis or thoracotomy. Anamnesis also includes an important place in emergency patient evaluation. For example, patients who were run over in road traffic accidents or those crushed in motor vehicle accidents are expected to have severe intra-thoracic injuries. Deceleration injuries indicate potential injuries to aorta and large airway. In patients admitted with symptoms of hypotension, distended neck veins may point to possible cardiac compression, tension pneumothorax or cardiac tamponade. On the other hand, collapsed neck veins are mainly associated with hypovolemic shock. Examining the chest wall may indicate paradoxical breathing due to flail chest and palpation may reveal fractures or subcutaneous emphysema. Isolated chest trauma resulting from blunt trauma is very rare. The most common extra-thoracic injuries in polytraumatized patients are cranial injuries, abdominal injuries, extremity fractures, pelvic fractures and vertebral fractures (13, 21, 22). Entrance and/or exit wounds should be observed, but such wounds should not be probed in penetrating thoracic injuries. If the entrance penetrating injury is below the fifth rib, it is necessary to investigate the possibility of diaphragmatic rupture and intra-abdominal organ injury. Abdominal injury should be evaluated in patients with rib fractures below the $7^{\text {th }}$ rib. Exploration of the abdomen in patients with blunt chest and abdominal injuries is recommended first. Thoracic exploration is performed if the patient's condition is still unstable after abdominal bleeding is controlled.

If there is no need for emergency thoracotomy or if developing tension pneumothorax is excluded, the patient is directed to radiological procedures. Radiographically overlooked or undiagnosed conditions are soft tissue injury, bone fractures, diaphragm injuries, mediastinal expansion, foreign body and pneumomediastinum. For example, up to $35 \%$ of the patients with a ruptured diaphragm appear to have normal chest X-ray $(23,24)$.

The first thing that should be done after the first interventions in thoracic trauma is the patient's analgesia and initiation of respiratory physiotherapy (25-28).

\section{Diagnostic Procedures with Thoracic Trauma}

Each blunt trauma patient should first undergo anteroposterior and lateral chest radiography (29). If there is a penetrating 
trauma, the entrance and exit wounds must be marked with radiosensitive markers. A surgeon carefully and systematically interprets chest radiographs in order not to overlook some possible injuries. The surgeon must check (30-32):

-The correct placement of the endotracheal tube

-Pneumothorax

-Tension pneumothorax

-Hemothorax

-Mediastinal emphysema: presence of air in the neck is the most specific finding and the most common cause is pneumothorax.

-Lung contusion: it cannot be seen on initial radiographs, but increased opacity should raise suspicion for further investigations.

-The protrusion of intra-abdominal organs into the thorax: on the left side the finding of hydroaeric collection may be mistaken for hydropneumothorax. Radiographic diagnosis of diaphragmatic rupture on the right side is difficult, as the liver is most commonly herniated organ. Elevation of the right hemidiaphragm should raise suspicion for further investigations.

-Fractures

-Projectiles in the thorax

-Mediastinal expansion: it is a major finding indicating aortic rupture. It is significant when it is larger than $8 \mathrm{~cm}$.

When the patient's condition is relativelystable, it is recommended to use chest $\mathrm{CT}$ in additional diagnostic procedure. Ultrasound is a useful method for evaluation of the subdiaphragmatic space findings and when small collections of fluid in the pleural space are detected, and also for cardiac evaluation.

\section{Monitoring of Thoracic Trauma}

The recommended parameters to monitor in thoracic trauma are arterial pressure, heart rate (obtained by electrocardiogram), central venous pressure, cardiac index, arterial $\mathrm{PO}_{2}, \mathrm{PCO}_{2}$ and $\mathrm{pH}$, and hematocrit value (33-37). Initial hematocrit values may be unreliable, especially in patients with excessive blood loss who receive crystalloid solutions. Hematocrit value can be accepted as a useful tool for determining the type of fluid rather than the fluid volume replacement. During replacement, it is important to stabilize the systolic pressure at $90-\mathrm{mmHg}$ in order to correct hypovolemia and to prevent hypervolemia.

\section{Shock in Thoracic Trauma}

In the early stages of shock, venous flow to the heart (preload) is reduced due to the loss of circulating fluid, which causes decreased cardiac output and the development of hypotension and tissue hypoperfusion. The body strives to maintain a normal circulating volume by moving fluid from tissues into blood vessels, by increasing heart rate due to activation of the sympathetic nervous system and by reduction of diuresis due to vasoconstriction. In later stages of shock, at the cellular level hypoxia is compensated by anaerobic metabolism and lactic acid production, leading to the development of metabolic acidosis. If the shock is left untreated, edema occurs and the cells lose functions. For this reason, correct fluid replacement therapy should be initiated immediately (35). The average blood loss per fractured rib is approximately $150 \mathrm{~mL}$, and in hemothorax it can be $2 \mathrm{~L}$.

\section{Acute Respiratory Distress Syndrome}

It is a life-threatening condition and is characterized by noncardiogenic pulmonary edema, hypoxemia, decreased lung compliance, intrapulmonary shunt and progressive pulmonary fibrosis in the late stage (36).

-Acute lung injury

-ARDS

In the first group, there is mild hypoxemia. In the second group, there is severe hypoxemia. Common features include acuteness, bilateral infiltrates and pulmonary artery occlusion. Predisposing risk factors for the first group are pulmonary contusion, aspiration of gastric contents, pneumonia, inhalation injury and drowning, and severe traumatic shock, head trauma, abdominal sepsis, burns, fat embolism, excessive volume replacement and DIC for the second group $(38,39)$. Clinical manifestations include tachypnea and tachycardia during the first 12 hours. The patients use auxiliary respiratory muscles, and on auscultation they have high-pitched expiratory crackles. Progressive hypoxia, hypercapnia, and acidosis are observed. Chest X-ray shows diffuse spotty infiltrations. The treatment of ARDS requires mechanical ventilation. The primary aim is to keep the alveoli open. Therefore, positive end-expiratory pressure (PEEP) is kept high. Fluid should be reduced in order to prevent pulmonary edema. The intravascular volume should be maintained at the lowest level. Vasopressors and inotropes can be used, and nitric oxide inhalation can be performed $(40,41)$. The effect of steroids on ARDS is only in preventing fibrosing alveolitis.

\section{Blunt Chest Injuries}

Chest wall contusion and hematoma are the most common thoracic injuries. Being mostly extrapleural, these injuries do not require surgery (18). Rib fractures occur in about $35 \%$ of thoracic injuries. Mortality is approximately $10 \%$ in elderly people over 
65 years. Rib fractures in children are rare, since the chest wall in children is very flexible, and the mortality rate is about $5 \%$. A severe traumatic force is required for fracture of first, second and third ribs posteriorly and first and second ribs anteriorly (19). Injuries of large blood vessels or tracheobronchial tree should be kept in mind in these fractures. Flail chest is a medical condition when three adjacent ribs are double-broken unilaterally. The frequency of flail chest is about $5 \%$. There is paradoxical respiration. The injured segment of the chest wall is drawn inward during inspiration and is drawn outward during expiration. The treatment of flail chest can be conservative or operative. Conservative treatment is recommended in patients with posterior type of flail chest without dyspnea. The application of mechanical ventilation with PEEP should be tried as a last chance for patients who will undergo surgery. If no result is obtained, surgery is required (21).

Sternal fractures result from blunt trauma with high-energy. They are often associated with multiple rib fractures. Sternal fracture is typically transverse and localized to the upper and middle parts of body of sternum. If the broken fragments were pushed over to the mediastinum, surgery would be indicated.

Lung contusion represents parenchymal laceration accompanied by intra-alveolar hemorrhage. Chest CT is the gold standard. A contusion involving more than $30 \%$ of lung parenchyma requires mechanical ventilation. Emergency surgery is needed in only $5 \%$. The indications include contusions with a massive air leak and injuries with massive intra- thoracic hemorrhage $(1500 \mathrm{~mL}$ of blood on insertion of the thoracic drain or $200 \mathrm{~mL}$ of blood every 4 hours, with continuous replacement).

Traumatic injuries of the trachea and bronchi present with hemoptysis, localized pain, neck contusion, subcutaneous emphysema, inspiratory stridor, hoarseness, progressive dyspnea and Hamman's sign (auscultatory findings of "crackling" synchronized with the heartbeat and breathing) in the early period, and dyspnea, stridor and distal infections in the late period. They are not often diagnosed immediately. Fiberoptic bronchoscopy is the gold standard in suspected cases (31).

Foreign bodies in the tracheobronchial tree is often seen in the injured with lost consciousness, in patients with dysphagia and in small children. Posteroanterior chest radiography should be performed first. Diagnosis and treatment are combined in patients with suspected radiological findings and anamnesis. It is treated by rigid bronchoscopy. In case of chronic foreign bodies, with developed granular tissue around the foreign body, bleeding or perforation can be seen in this area, but it is rare. Treatment of this complication is $100 \%$ surgery.
Traumatic injuries of diaphragm occur in $4 \%$ of all blunt traumas. This rate is $15 \%$ in stab wounds and $45 \%$ in gunshot wounds. Diagnosis is made based on the radiographic findings. Undiagnosed patients may present with strong pain within the chest, dyspnea and signs of obstruction in small and large intestine. Treatment is surgical. Diaphragmatic injuries diagnosed in the early period are treated by laparotomy and injuries diagnosed in the late period are treated by thoracotomy. Because it is more difficult to reach the diaphragm by thoracotomy, and thoracotomy is preferred because of the adhesions in the chest in late cases (34).

Traumatic pneumothorax is the presence of air in the pleural space and occurs as a consequence of the laceration of the visceral pleura and lung parenchyma. The laceration of parietal pleura can contribute to the development of subcutaneous emphysema. There is no necessity of associated rib fracture in blunt traumas. During sudden chest compression, alveolus rupture may be seen due to increased alveolar pressure. Air that comes out in the interstitial area by dissection toward the visceral pleura or mediastinum results in pneumothorax or mediastinal emphysema. In addition, pneumothorax may occur due to lung injury or air entering from outside as a result of penetrating injuries. Pneumothorax is surgically treated by the thoracic drainage. If there is no previous lung disease, decreased vital capacity is well tolerated by the patient. However, in case of previous lung diseases, a progressive course from respiratory insufficiency and alveolar hypoventilation to metabolic acidosis may occur. There are 3 types pneumothorax, namely simple, open and tension type. Open pneumothorax is often associated with penetrating injury, while the remaining two are mainly seen at the blunt injury of the chest.

Pneumothorax occurs due to the injury of the following structures (39):

-Thoracic wall

-Lung parenchyma

-Tracheobronchial tree out of the part covered by the mediastinal pleura

-Esophagus and mediastinal pleura

-Diaphragm and associated perforations of intestines

PA chest X-rays in the standing position is the gold standard in the diagnosis. In the management of tension pneumothorax, a large cannulated injector or angiocath should be inserted to drain the air if the patient is going to be transferred or if a drain 
is to be inserted. Minimal pneumothorax or patients presenting late to hospital with minimal pneumothorax may be treated conservatively, but this is rare.

Subcutaneous emphysema defines the presence of the air within the subcutaneous tissue. It should not be confused with gas due to abscess formation within the tissue. The mediastinal emphysema will gradually intensify in the head and neck region of the patient due to the upward movement of the air. This is not clinically relevant unless it causes dyspnea (32). The areas that disturb the patient may be carefully drained with a subcutaneous needle.

Traumatic hemothorax marks the presence of blood within the pleural space. Besides blunt and penetrating traumas, it can also be seen as iatrogenic. After surgery of thoracic spine, especially vertebrae at the level Th4-Th6, hemothorax can developed even a few days after the surgery. Empyema may develop over hemothorax. The decision of hemothorax is not given by the color of the fluid; the hematocrit value of the pleural fluid should be at least $50 \%$ of the blood hematocrit value. Incidence of hemothorax in blunt trauma is $38 \%$ in patients with rib fracture and 35\% without rib fracture. The occurrence of hemothorax is more frequent when the fractured rib-ends are dislocated. The treatment of massive hemothorax is surgery. The non-massive hemothorax cases are followed by thoracic drainage. The tomography is the gold standard in the diagnosis (39-42).

\section{Absolute Indications for Thoracic Drainage}

-Traumatic pneumothorax

-Tension pneumothorax

-Bilateral pneumothorax

-Massive hemothorax

-Associated collection of blood and air - hemopneumothorax

\section{Indications for Re-Drainage}

-Development of empyema at the drained hemothorax

-Encapsulated hydroaeric collections

-Collections of fluid and air

In patients with general anesthesia requirement for surgeries of extra-thoracic organs, PEEP levels and ventilation pressures should be kept low, and attention should be paid to the possibility of development of the tension pneumothorax. Preventive drainage of the thorax is not indicated when the obvious signs of pneumothorax are not present.

\section{Ethics}

Peer-review: Internally peer-reviewed.

\section{Authorship Contributions}

Concept: N.T., T.M., A.A., M.E., Design: N.T., T.M., A.A., M.E., Data Collection or Processing: T.M., A.A., C.K., M.E., Analysis or Interpretation: N.T., T.M., A.A., M.E., Literature Search: T.M., S.T., A.A., M.E., Writing: T.M., C.K., S.T., A.A., M.E., I.A.

Conflict of Interest: No conflict of interest was declared by the authors.

Financial Disclosure: The authors declared that this study received no financial support.

\section{REFERENCES}

1. Scottish Intercollegiate Guidelines Network (SIGN), Early management of patients with a head injury: a national clinical guideline. Edinburgh: SIGN; 2000. (SIGN guideline 46)

2. Ersahin Y, Gulmen V, Mutluer S. Growing skull fractures (craniocerebral erosion), Neurosurg Rev 2000;23:139-44.

3. León-Carrión J, Domínguez-Morales Mdel R, Barroso y Martín JM, MurilloCabezas F. Epidemiology of traumatic brain injury and subarachnoid hemorrhage. Pituitary 2005;8:197-202.

4. Rangel-Castilla L, Gopinath S, Robertson CS. Management of intracranial hypertension. Neurol Clin 2008;25:521-41.

5. Kim YI, Park SW, Nam TK, Park YS, Min BK, Hwang SN. The Effect of Barbiturate Coma Therapy for patients with severe intracranial hypertension. A 10- year experience. J Korean Neurosurg Soc 2008;44:141-5.

6. Howard JL, Cipolle MD, Anderson M, Sabella V, Schollenberger D, Li PM, et al. Outcome after decompressive craniectomy for the treatment of severe traumatic brain injury. J Trauma 2008;65:380-5; discussion 3856

7. Torbic H, Forni AA, Anger KE, Degrado JR, Greenwood BC. Antiepileptics for seizure prophylaxis after traumatic brain injury. Am J Health Syst Pharm 2013;70:2064-7

8. Spinal cord injury facts and figures at a glance. J Spinal Cord Med 2012:35:197-8

9. Bickenbach J, Officer A, Shakespeare T, von Groote P. International Perspectives of Spinal Cord Injury. World Health Organization (WHO) 2013;978:156466.

10. Evaniew N, Noonan VK, Fallah N, Kwon BK, Rivers CS, Bailey CS, et al Methylprednisolone for the treatment of patients with acute spinal cord injuries: A propensity score-matched cohort study from a Canadian multicenter spinal cord registry. J Neurotrauma 2015;32:1674-83.

11. LoCicero J, Mattox KL. Epidemiology of chest trauma. Surg Clin North Am 1989;69:5.

12. Shorr RM, Rodriguez A, Indeck MC, Crittenden MD, Hartunian S, Cowley RA. Blunt chest trauma in elderly. J Trauma 1989;29:234-7.

13. Besson A, Saegesser F. Color Atlas of Chest Trauma and Associated Injuries Vol.1 oradell. NJ: Medical Economics, 1983, p.9.

14. Haxhija EQ, Nöres H, Schober P, Höllwarth ME. Lung contusion-lacerations after blunt thoracic trauma in children. Pediatr Surg Int 2004;20:412-4. 
15. Shackford SR. Blunt chest trauma: the intensivists's perspective. Intensive Care Med 1986;1:125.

16. Smith RS, Fry WR, Tsoi EK, Morabito DJ, Koehler RH, Reinganum SJ, et al. Preliminary report on videothoracoscopy in the evaluation and treatment of thoracic injury. Am J Surg 1993;166:690-3; discussion 693-5.

17. Hood-Boyd-Culliford: Thoracic Trauma, W.B Saunders Company, 1989

18. Galan G, Peñalver JC, París F, Caffarena JM Jr, Blasco E, Borro JM, et al. Blunt chest injuries in 1696 patients. Eur J Cardiothorac Surg 1992;6:284-7.

19. Glinz W. Symposium paper: priorities in diagnosis and treatment of blunt chest injuries. Injury 1986;17:318

20. Kulshrestha P, Iyer KS, Das B, Balram A, Kumar AS, Sharma ML, et al. Chest injuries. A clinical and autopsy profile. Trauma 1988;28:844-7.

21. Liman ST, Kuzucu A, Tastepe AI, Ulasan GN, Topcu S. Salih Topcu Chest injury due to blunt trauma. Eur J Cardiothorac Surg 2003;23:374-8.

22. Glinz W. Causes of early death in thoracic trauma. In Webb WR, Besson A (eds): Thoracic Surgery: Surgical Management of Chest Injuries. Vol.7. St.Louis: Mosby-Year Book, 1991.

23. Murray JA1, Demetriades D, Cornwell EE 3rd, Asensio JA, Velmahos G, Belzberg $\mathrm{H}$, et al. Penetrating left thoracoabdominal trauma: the incidence and clinical presentation of diaphragm injuries. J Trauma 1997;43:624-6.

24. Campbell DB. Trauma to the chest wall, lung, and major airways. Semin Thorac Cardiovasc Surg 1992;4:234.

25. Feliciano DV, Bitando CG, Mattox KL, et al. A 1 year experience with 450 vascular and cardiac injuries. Ann Surg 1984;199:177.

26. Feliciano DV, Bitondo CG, Cruse PA, Mattox KL, Burch JM, Beall AC Jr, et al. Liberal use of emergency center thoracotomy. Am J Surg 1986;152:6549.

27. Fisher RP, Jelense S, Perry ST Jr. Direct transfer to operating room improves care of trauma patients: A simple economically feasible plan for large hospital. JAMA $1978 ; 240: 1731-2$.

28. Flynn TC, Ward RE, Miller PW. Emergency department thoracotomy. Ann Emerg Med 1982;11:413-6.
29. Obertacke U, Joka TH, Jochum M, Kreuzfelder E, Schönfeld W, Kirschfink M. Posttraumatische alveoläre Veränderungen nach Lungenkontusion. Uniallchirurg 1991;94:134-8.

30. Pearson FG, Deaslauriers J, Ginsberg RJ, Hiebert CA, McKneally MF, Urschel HC Jr. Trauma, pathophysiology and initial management, In thoracic surgery. Churchill Livingstone, p. 1532, 1995.

31. Sinha P, Sarkar P. Late clotted haemothorax after blunt chest trauma. J Accid Emerg Med 1998;15:189-91.

32. Sisley AC, Rozycki GS, Ballard RB, Namias N, Salomone JP, Feliciano DV. Rapid detection of traumatic effusion using surgeon-performed ultrasonography. J Trauma 1998;44:291-6; discussion 296-7.

33. Polk HC Jr. Factors influencing the risk of infection after trauma. Am J Surg 1993;165(2A Suppl):2S-7S.

34. Shorr RM, Crittenden M, Indeck M, Hartunian SL, Rodriguez A. Blunt thoracic trauma. Ann Surg 1987;206:200-5.

35. Valeri CR. Optimal use of blood products in the treatment of hemorrhagic schock. Surg Rounds 1981;4:38.

36. Verheij J, van Lingen A, Raijmakers PG, Rijnsburger ER, Veerman DP, Wisselink W, et al. Effect of fluid loading with saline or colloids on pulmonary permeability, oedema and lung injury score after cardiac and major vascular surgery. Br J Anaesth 2006;96:21-30.

37. West JG, Trunkey DD, Limm RC. Systems of trauma care. Arch Surg 1979;114:455-60.

38. Webb WR, Besson A. Thoracic Surgery: Surgical Management of Chest injuries. Vol 7. International Trends in General Thoracic Surgery.

39. Mattox KL, Allen MK. Systematic approach to pneumothorax, haemothorax, pneumomediastinum and subcutaneous emphysema. Injury 1986;17:309.

40. Freixinet J, Beltrán J, Rodríguez PM, Juliá G, Hussein M, Gil R, et al. Indicators of Severity in Chest Trauma. Arch Bronconeumol 2008;44:257-62.

41. Weil PH, Margolis IB. Systematic approach to traumatic hemothorax. Am J Surg 1981;142:692.

42. Muckart DJ. Delayed pneumothorax and haemothorax following observation for stab wounds of the chest. Injury 1985;16:247-8. 